\title{
Highlights and recent developments in skin allergy and related diseases in EAACl journals (2018)
}

\author{
C. A. Akdis ${ }^{1}$, J. Bousquet $2,3,4,5^{*}$ (1) , C. E. Grattan ${ }^{6}$, P. A. Eigenmann, K. Hoffmann-Sommergruber ${ }^{8}$, I. Agache ${ }^{9}$ \\ and M. Jutel ${ }^{10}$
}

\begin{abstract}
The European Academy of Allergy and Clinical Immunology (EAACI) supports three journals: Allergy, Paediatric Allergy and Immunology as well as Clinical and Translational Allergy. The major goals of EAACl include (i) supporting health promotion in which the prevention of allergy and asthma plays a critical role and (ii) disseminating the knowledge of allergy to all stakeholders including the EAACl junior members. Substantial progress was made in 2018 in the identification of basic mechanisms of atopic dermatitis and urticaria and the translation of these mechanisms into clinics. Many large epidemiologic studies and meta-analyses have been the highlights of the last year.
\end{abstract}

Keywords: Atopic dermatitis, Urticaria, EAACl

\section{Introduction}

The European Academy of Allergy and Clinical Immunology (EAACI) supports three official journals: Allergy, Paediatric Allergy and Immunology as well as Clinical and Translational Allergy. The major goals of EAACI include (i) supporting health promotion in which the prevention and control of allergy plays a critical role and (ii) disseminating the knowledge of allergy to all stakeholders including the EAACI Junior Members. The EAACI journals reported advances in allergy in 2017 [1,2] and 2018 [3]. This paper summarizes the achievements of 2018 in atopic dermatitis and urticaria. The position papers and EAACI/WAO/GA²LEN guidelines are summarized.

\section{Atopic dermatitis \\ Mechanisms}

Atopic dermatitis (AD), commonly known as eczema, is a chronic skin disorder associated with skin barrier dysfunction that is characterized by dry, itchy skin (pruritus).

\footnotetext{
*Correspondence: jean.bousquet@orange.fr

2 MACVIA-France, Fondation Partenariale FMC VIA-LR, CHU Arnaud de Villeneuve, 371 Avenue du Doyen Gaston Giraud, 34295 Montpellier Cedex 5, France

Full list of author information is available at the end of the article
}

Interleukin-31 (IL-31) secreted by T-helper $2\left(\mathrm{~T}_{\mathrm{H}} 2\right)$ cells induces the itchy symptoms. The role of IL-31 in the pathogenesis of $\mathrm{AD}$ and novel therapeutic strategies targeting its receptor have been recently reviewed [4].

$\mathrm{AD}$ patients have an altered skin microbiome composition characterized by an increased colonization of Staphylococcus aureus (S. aureus) which is associated with disease severity. In addition, $A D$ patients have a reduced expression of toll-like receptor-2 (TLR2) receptors in Langerhans cells (LC) and inflammatory dendritic epidermal cells (IDEC) compared to healthy controls [5]. Ex vivo human skin models were treated with the TLR2 ligand Pam3Cys, a mimic of $S$. aureus. In contrast to healthy skin, LC and IDEC lacked maturation and had a strong spontaneous migratory activity. The supernatant of AD skin showed significantly reduced levels of IL-6 and IL-10 and an overexpression of IL-18.

A novel mechanism involved in epidermal barrier dysfunction was recently reported in a mouse model of allergic inflammation and in AD patients [6]. It was found that IL-24 downregulates filaggrin expression and is produced in keratinocytes by the stimulation of IL-13 in a periostin-dependent manner. Elevated levels of IL-24 and activated STAT3 were found in the epidermis of the mouse model and of $\mathrm{AD}$ patients. 
The role of the pruritogenic mediator endothelin-1 (ET1) in the pathogenesis of $A D$ was recently investigated in mouse bone marrow-derived dendritic cells (BMDCs) [7]. ET-1 was significantly upregulated in the epidermis of $\mathrm{AD}$ patients and stimulated the production of Th1 and Th17 cytokines from BMDCs in a concentration-dependent manner. This switch to a Th17/Th1 response may contribute to the chronic lesions in $\mathrm{AD}$ patients.

Studies in a human AD-like mouse model revealed novel mechanistic insights that support a link between cell infiltration of the hypodermis to local mast cell activation and elevated levels of sphingosine-1-phosphate (S1P) after antigen exposure [8]. Neuromedin U (NMU) released from keratinocytes induces the degranulation of mast cells via pertussis toxin-sensitive $G$ protein-coupled receptors [9].

Exposure to air pollution aggravates the symptoms of $\mathrm{AD}$ in children in the population studies. Variability in the individual patient's response from individual susceptibility needs to be explored. In 89 children aged 0-6 years with AD, daily manifestation of symptoms was recorded for an average of 257 days and confronted to pollution levels [10]. In the overall analysis, ozone, particulate matter $<10 \mu \mathrm{m}\left(\mathrm{PM}_{10}\right), \mathrm{NO}_{2}, \mathrm{SO}_{2}$, and $\mathrm{CO}$ had a significantly positive association, whereas temperature and relative humidity were negatively associated with $\mathrm{AD}$ symptoms. However, responses of AD children to air pollution and weather variables were inconsistent among individuals.

\section{Epidemiologic studies}

Earlier studies have shown an association between the month of birth and the severity of atopic dermatitis. In one study, Armenian children were investigated for the severity of their eczema in relation to the month of birth. It was found that children born in the winter had more severe eczema. The authors hypothesized, in relation to earlier findings, that the severity of eczema could be related to an early exposure to common environmental allergens [11].

Data of the epidemiology of atopic dermatitis were collected in an online survey from patients in the US, Canada, France Germany, Italy, Spain, UK, and Japan [12]. The respondents were characterized and selected if they met the UK Working Party/ISAAC criteria and had been previously diagnosed by a physician. There was a decreased prevalence of $A D$ with age and, except for the US, a higher prevalence among women. Only a small portion suffered severe $\mathrm{AD}$ across all regions. The severity of $\mathrm{AD}$ varied according to the different assessment scales used (Patient-Oriented SCORAD, Patient-Orientated Eczema Measure, and Patient Global Assessment).
The plan for the Preventing Atopic Dermatitis and ALLergies (PreventADALL) in children study has been recently reported [13]. Its main objectives are the prevention of allergic diseases by assessing early-life risk factors, including microbial diversity, diet, lifestyle, and geneenvironment interactions, using simple cost-efficient strategies. Children born by cesarean section and by assisted birth are at an increased risk of developing flexural eczema in childhood/early adulthood [14].

There are limited and conflicting reports on the longterm clinical course of AD. A systematic review and meta-analysis of 2080 references and 7 birth cohort studies with a total of 13,515 participants indicated that there is a similar prevalence of $\mathrm{AD}$ in childhood and adolescence [15]. Undergoing thymectomy in early childhood was associated with a reduced risk of AD but was only statistically significant in a model where time-dependent changes were not included [16].

\section{Severity scores}

Reliability and validity of the AD Symptom Score (ADSS) were studied in 307 children and adolescents with AD [17]. Parents or caregivers were asked to record daily symptoms of the patients (itching, sleep disturbance, erythema, dryness, oozing, and edema) using a scale of 0-4. The ADSS was found be a useful tool for the self-assessment of skin symptoms in children with AD.

A recent study has validated the use of patient-reported $\mathrm{AD}$ severity assessment using a single question with a simple scoring system of mild, moderate and severe [18]. The responses from 265 adult patients significantly correlated with other outcome measures, including oSCORAD, SCORAD, EASI, BSA, NRS-itch, POEM, and DLQI, and were further confirmed by a dermatologist.

\section{Multimorbidities}

The association between $\mathrm{AD}$ and cardio-metabolic risk factors is not fully understood, partly due to the lack of validated questionnaire-based methods to identify adults with $\mathrm{AD}$. In an attempt to investigate the association of cardio-metabolic risk factors in AD patients, data collected from 9656 Danish adults were analyzed using three different cardiovascular risk questionnaires [19]. There was a large discrepancy in the results from each questionnaire and so a definite conclusion could not be reached. These results highlight the need for clinical diagnosis of $\mathrm{AD}$ by a dermatologist and the fact that responses from questionnaires should be carefully interpreted.

In a nationwide, population-based cohort study (Taiwan's National Health Insurance Research Database), the association between obstructive sleep apnoea (OSA) and AD was sought in 120,736 children [20]. This study revealed an increased risk of obstructive sleep apnoea 
in children with $\mathrm{AD}$. Therefore, comprehensive evaluation and aggressive risk reduction for obstructive sleep apnoea are recommended in these patients.

AD can significantly impact quality-of-life to the point that it can affect mental health. Data collected from the Danish health registry and a population-based questionnaire indicated that $\mathrm{AD}$ patients had an increased risk of mild anxiety, depression and suicidal ideation compared to non-AD subjects but did not result in psychiatric hospitalization or suicide [21]. Early antihistamine exposure for the treatment of $\mathrm{AD}$ was associated with increased attention-deficit/hyperactivity disorder symptoms in children aged $6-12$ years. The study questionnaire asked parents whether their child had used systemic antihistamines to treat AD but did not distinguish between sedating and non-sedating $\mathrm{H} 1$-antihistamines. The authors noted that there is a need to further investigate the role of sleeping problems and its treatment with (sedating) antihistamines in young children concerning early-life development and the potential risk for ADHD in children with $\mathrm{AD}$ [22].

\section{Prevention and treatment}

The protective effect of the Bacillus Calmette-Guerin (BCG) vaccination to reduce the risk of allergic diseases, including $\mathrm{AD}$, is unclear. A recent study from the Danish Calmette (2012-2015) found that the clinical outcome of the BCG vaccination differed for children with and without atopic predisposition [23]. The cumulative incidence of $\mathrm{AD}$ was reduced by $16 \%$ in infants with an atopic predisposition. Oral antigen administration in mice has a protective effect against $\mathrm{AD}$ by promoting the increased expression of genes involved in the regulation of Th2 inflammatory responses and skin barrier function [24].

A randomized, double-blinded, placebo-controlled trial assessed the effects of melatonin administration on disease severity and sleep quality in 70 children with $\mathrm{AD}$ [25]. Overall, melatonin supplementation had beneficial effects on disease severity, serum total IgE levels, and on the Children's Sleep Habits Questionnaire (CSHQ).

The efficacy of allergen-specific subcutaneous immunotherapy (SIT) as a curative treatment for atopic dermatitis remains controversial. A murine model was established to investigate the clinical efficacy of SIT [26]. The DfE-treated NC/Nga mice showed clinical, histological and immunological improvement with elevated levels of IL-10 producing Treg cells and NK cells.

The potential use of superoxide dismutase 3-transducer (SOD3) mesenchymal stem cells (MSCs), as a novel cell-based therapy for $\mathrm{AD}$, was demonstrated in a mouse model of OVA-induced AD-like skin inflammation [27]. Mice with AD that received a subcutaneous administration of SOD3-MSCs showed an improvement of skin thickening and inflammation compared to control mice. The reduced skin inflammation was attributed to the inhibition of the histamine $\mathrm{H}_{4}$ receptor, MAPK/NFkB activation and JAK/STAT signalling.

Maternal exposure to a farming environment protects newborns against allergic diseases including AD by modulating the neonatal TLR-Tregs-Th axis [28].

In cats and dogs, there are pathogenetic similarities with human AD. This is often a difficult disease for animals and their owners [29].

\section{Urticaria \\ Mechanisms and risk factors}

Salt-dependent aquagenic urticaria is rare and has only ever been reported in adults, especially young women. Two cases of salt-dependent aquagenic urticaria have now been reported in children [30].

Two additional cases of cancer and chronic urticaria have also been reported [31, 32]. The urticaria resolved once the tumour was removed. A review of 25 previous reports of chronic urticaria and malignancy raises the possibility that $\mathrm{CU}$ and malignancies are linked in some patients [3].

Exposure to phthalates increases the risk of acute urticaria in children [33].

A recent study in 49 Caucasian CSU patients found elevated levels of specific IgE against a mix of Staphylococcus aureus enterotoxins (SEs) in $51 \%$ of patients compared to $33 \%$ in healthy controls [34]. Total serum IgE levels and CSU disease activity were correlated with Staphylococcus enterotoxin B-IgE (SEB-IgE) levels. These results suggest a role of SEs IgE antibodies in the pathogenesis of CSU, in keeping with the current hypothesis of autoallergy being important in some patients.

CSU patients are known to have elevated levels of C-reactive protein (CRP) and it is a sensitive inflammatory biomarker for the diagnosis and disease activity of CSU. In a retrospective study of 1253 CSU patients, higher levels of CRP were associated with autologous serum skin test positivity, arterial hypertension, urticaria activity, quality of life impairment, inflammatory and coagulation markers, and poor response to antihistamines [35].

A systematic review assessed the relationship between vitamin D and CSU [36]. Fourteen studies (1321 CSU cases and 6100 controls) were considered. Twelve studies showed statistically significant lower serum vitamin D levels in CSU patients than in the controls. Vitamin D deficiency was reported more commonly for CSU patients $(34.3-89.7 \%)$ than for controls $(0.0-68.9 \%)$ in 6 studies. Seven showed disease improvement after highdosages of vitamin D supplementation. Well-designed 
randomized placebo-controlled studies are needed to determine the cut-off levels of vitamin D for supplementation and treatment outcomes.

\section{Epidemiologic studies}

A physician-based online survey conducted in 5 European countries (United Kingdom, Germany, Italy, France, and Spain) assessed the annual diagnosed prevalence, disease characteristics, and treatment of $\mathrm{CU}$ (chronic inducible and spontaneous urticaria) and CSU in children [37]. Across the 5 European countries, the one-year diagnosed prevalence of CU and CSU in paediatric patients was $1.38 \%$ and $0.75 \%$. This study showed a prevalence of $\mathrm{CSU}$ in children comparable to adults. Angioedema was reported in $6-14 \%$ of patients. A large proportion of CSU paediatric patients $(40-60 \%)$ were treated with H1-antihistamines at approved doses and $16-51 \%$ received H1-antihistamines at higher doses. Approximately $1 / 3$ of paediatric CSU patients remained uncontrolled with H1-antihistamines at approved/higher doses.

A systematic review was carried out in children under 12 years of age with CSU to assess interventions and comorbidities [38]. The systematic review included 9 reports (633 children). Five comorbidities and laboratory anomalies were found to be associated with CSU: atopy (28.1\%), positive autologous serum skin test (36.8\%), thyroid anomalies $(6.4 \%)$ and detectable antinuclear antigen (10.4\%), seroprevalence for Helicobacter pylori (21.1\%), low vitamin D level (69.1\%), and psychiatric disorders (70.4\%). Only one study allowed for comparison with a control group.

The ASSURE-CSU (ASsessment of the Economic and Humanistic Burden of Chronic Spontaneous/Idiopathic URticaria PatiEnts) study analyzed the socioeconomic burden of CSU. A recent post hoc analysis of the ASSURE-CSU study evaluated 673 patients with inadequately controlled CSU and revealed significant differences between patient- and physician-reported angioedema [39]. These were classified-according to the availability of medical records and patient-reported diagnosis-as : Yes-angioedema (concordant) (40.3\%), No-angioedema (concordant) (26.9\%) and Misaligned (32.8\%). The frequency of angioedema in CSU patients is under-recognized by physicians, even though it has significant impact on quality-of-life, work productivity and health care resource utilization. The international EAACI/GA²LEN/EDF/WAO methods report for the guidelines and recommendations for the management and diagnosis of angioedema has been recently revised [40].

OPuS-2 is a Phase 3 clinical study that investigated the efficacy and safety of avoralstat, a kallikrein inhibitor, on hereditary angioedema (HAE) caused by mutations in the SERP-ING1 gene that leads to a deficiency of the kallikrein inhibitor, C1 inhibitor (C1-INH) [41]. Unlike in the previous Phase 1 and Phase 2 clinical studies, the treatment efficacy with $500 \mathrm{mg}$ avoralstat, 3 times daily for 12 weeks, could not be demonstrated. However, these patients experienced shortened angioedema episodes and improved QoL as assessed using the Angioedema Quality of Life Questionnaire (AE-QoL). In a separate study, the natural course of an oedematous attack in a patient with hereditary angioedema due to $\mathrm{C} 1$-INH deficiency was monitored for $96 \mathrm{~h}$. The concentration of the C4a activation product significantly increased during the prodromal period suggesting that $\mathrm{C} 4 \mathrm{a}$ could potentially be used as a prognostic biomarker of an edematous attack [42]. A novel type of HAE with normal C1-INH levels has been identified as having a mutation in the plasminogen gene and is manifested as swelling of the face/lips and tongue [43].

\section{Diagnosis and severity scores}

The EAACI/GA 2 LEN/EDF/WAO guidelines for the definition, classification, diagnosis and management of urticaria have been recently revised and updated [44-46].

CSU disease activity is commonly measured using the urticaria activity scores UAS7 and UAS7 ${ }_{\mathrm{TD}}$. The main differences between the two is that in UAS7, symptoms are recorded daily whilst in $\mathrm{UAS7}_{\mathrm{TD}}$, symptoms are recorded twice a day, and that they use different wheal scoring systems. The two different versions showed similar results when assessing the severity of $130 \mathrm{CSU}$ patients, suggesting the preferential use of the simpler UAS7 scoring system [47].

\section{Multimorbidities}

There are limited reports on the association between $\mathrm{CU}$ and systemic lupus erythematosus (SLE). The logistic regression analysis of 2000-2011 claims data from the Taiwanese National Health Insurance Research Database of 2105 children suffering from SLE. It is indicated that there is an increased risk of developing acute urticaria and CU, particularly in female patients [48]. A comprehensive literature review indicated that chronic hepatitis $\mathrm{B}$ and $\mathrm{C}$ are not associated with CSU and so routine screening for these viral infections in CSU patients is not necessary [49].

\section{Treatment}

Bilastine is a $\mathrm{H}_{1}$-antihistamine prescribed for the treatment of CSU at a standard daily dose of $20 \mathrm{mg}$. Some patients may benefit from updosing to $40 \mathrm{mg}$ and up to $80 \mathrm{mg}$ for the most severe cases [50]. The X-ACT study is a clinical phase III to examine the effectiveness of omalizumab for the treatment of CSU 
patients with angioedema refractory to high doses of $\mathrm{H}_{1}$-antihistamines. The reduction in angioedema symptoms when CSU patients were treated with $300 \mathrm{mg}$ omalizumab significantly improved the QoL and psychological well-being as assessed by the Angioedema Quality of Life and the Dermatology Life Quality Index (DLQI) questionnaires [51].

Findings from the Icatibant Outcome Survey, a cohort observational study, showed that the effectiveness of Icatibant for the treatment of hereditary angioedema attacks is not affected by body weight [52].

Two case reports of omalizumab being effective in normo-complementaemic urticarial vasculitis (UV) reopens discussion about the pathogenesis of UV and its relationship with CSU [53]. CSU patients have elevated levels of IgE to tissue factor and thyroglobulin which are reduced in patients treated with CSU [54]. The IgE levels can be used as a prognostic marker for the therapeutic response of omalizumab. The IgE levels in CSU patients treated with omalizumab at baseline [55] and after 4 weeks of treatment [56] were significantly lower in non-responders compared to partial and complete responders.

Even though the administration of $300 \mathrm{mg}$ omalizumab may be successful in the treatment of CSU patients who do not respond to antihistamines, it does not cure the disease and patients often relapse after the regimen is completed. The high cost of the drug has prompted The Italian Medical Agency to prohibit the administration of omalizumab beyond 1 year of treatment and so there is an urgent need for alternative therapies after 1 year. A study of 14 patients with complete response to omalizumab after 6 months $(300 \mathrm{mg} / \mathrm{month})$ demonstrated that half of the patients could be switched to a regimen of $150 \mathrm{mg} / \mathrm{month}$ for an additional 4 months as an add-on treatment to second-generation antihistamines [57].

Serum sickness-like reaction was observed in a child using omalizumab for CSU [58], having previously been reported only in an adult. This is included as a warning in the summary of product characteristics.

\section{Conclusion}

Many important papers have been published in EAACI journals this year.

\section{Abbreviations}

AD: atopic dermatitis; CSU: chronic spontaneous urticaria; CU: chronic urticaria.

\section{Acknowledgements}

None.

\section{Authors' contributions}

All authors have contributed to the design of the project and have written the paper. All authors read and approved the final manuscript.
Funding

None.

Availability of data and materials

Not applicable.

Ethics approval and consent to participate

Not applicable.

Consent for publication

All authors gave their agreement for the publication of the paper.

Competing interests

The authors declare that they have no competing interests.

\section{Author details}

${ }^{1}$ Swiss Institute of Allergy and Asthma Research (SIAF), University Zurich, Davos, Switzerland. ${ }^{2}$ MACVIA-France, Fondation Partenariale FMC VIA-LR, CHU Arnaud de Villeneuve, 371 Avenue du Doyen Gaston Giraud, 34295 Montpellier Cedex 5, France. ${ }^{3}$ INSERM U 1168, VIMA: Ageing and Chronic Diseases Epidemiological and Public Health Approaches, Villejuif, Université Versailles StQuentin-en-Yvelines, UMR-S 1168, Montigny le Bretonneux, France. ${ }^{4}$ Charité, Universitätsmedizin Berlin, Humboldt-Universität zu, Berlin, Germany. ${ }^{5}$ Department of Dermatology and Allergy, Comprehensive Allergy Center, Berlin Institute of Health, Berlin, Germany. ${ }^{6}$ St John's Institute of Dermatology, Guy's Hospital, London, UK. ${ }^{7}$ Pediatric Allergy Unit, University Hospitals of Geneva, Geneva, Switzerland. ${ }^{8}$ Department of Pathophysiology and Allergy Research, Medical University of Vienna, Vienna, Austria. ${ }^{9}$ Transylvania University Brasov, Brasov, Romania. ${ }^{10}$ ALL-MED Medical Research Institute, Wroclaw, Poland.

Received: 27 October 2019 Accepted: 12 November 2019

Published online: 20 November 2019

\section{References}

1. Bousquet J, Grattan C, Bieber T, Matricardi P, Simon HU, Wahn U, et al. Prediction and prevention of allergy and asthma in EAACI journals (2016). Clin Transl Allergy. 2017;7:46.

2. Wahn U, Matricardi PM, Bieber T, Bousquet J, Grattan C, Simon HU, et al. Food allergy in EAACI journals (2016). Pediatr Allergy Immunol. 2017;28(8):825-30

3. Bousquet J, Akdis CA, Grattan C, Eigenmann PA, Hoffmann-Sommergruber K, Hellings PW, et al. Highlights and recent developments in airway diseases in EAACI journals (2017). Clin Transl Allergy. 2018;8:49.

4. Furue M, Yamamura K, Kido-Nakahara M, Nakahara T, Fukui Y. Emerging role of interleukin-31 and interleukin-31 receptor in pruritus in atopic dermatitis. Allergy. 2018;73(1):29-36.

5. Iwamoto K, Numm TJ, Koch S, Herrmann N, Leib N, Bieber T. Langerhans and inflammatory dendritic epidermal cells in atopic dermatitis are tolerized toward TLR2 activation. Allergy. 2018;73(11):2205-13.

6. Mitamura Y, Nunomura S, Nanri Y, Ogawa M, Yoshihara T, Masuoka M, et al. The IL-13/periostin/IL-24 pathway causes epidermal barrier dysfunction in allergic skin inflammation. Allergy. 2018;73(9):1881-91.

7. Nakahara T, Kido-Nakahara M, Ohno F, Ulzii D, Chiba T, Tsuji G, et al. The pruritogenic mediator endothelin-1 shifts the dendritic cell-T-cell response toward Th17/Th1 polarization. Allergy. 2018;73(2):511-5.

8. Wedman PA, Aladhami A, Chumanevich AP, Fuseler JW, Oskeritzian CA. Mast cells and sphingosine-1-phosphate underlie prelesional remodeling in a mouse model of eczema. Allergy. 2018;73(2):405-15.

9. Matsuo Y, Yanase Y, Irifuku R, Takahagi S, Mihara S, Ishii K, et al. Neuromedin $\mathrm{U}$ directly induces degranulation of skin mast cells, presumably via MRGPRX2. Allergy. 2018;73(11):2256-60.

10. Noh SR, Kim JS, Kim EH, Jeon BH, Kim JH, Kim YM, et al. Spectrum of susceptibility to air quality and weather in individual children with atopic dermatitis. Pediatr Allergy Immunol. 2019;30(2):179-87.

11. Sargsyan A, Gupta J, Ghosh D. Association of severe atopic dermatitis with month of birth in armenian pediatric patients. Pediatr Allergy Immunol. 2018;29(6):655-6. 
12. Barbarot S, Auziere S, Gadkari A, Girolomoni G, Puig L, Simpson EL, et al. Epidemiology of atopic dermatitis in adults: results from an international survey. Allergy. 2018;73(6):1284-93.

13. Lødrup Carlsen KC, Rehbinder EM, Skjerven HO, Carlsen MH, Fatnes TA, Fugelli $\mathrm{P}$, et al. Preventing atopic dermatitis and ALLergies in childrenthe PreventADALL study. Allergy. 2018;73(10):2063-70.

14. Gerlich J, Benecke N, Peters-Weist AS, Heinrich S, Roller D, Genuneit J, et al. Pregnancy and perinatal conditions and atopic disease prevalence in childhood and adulthood. Allergy. 2018;73(5):1064-74.

15. Abuabara K, Yu AM, Okhovat JP, Allen IE, Langan SM. The prevalence of atopic dermatitis beyond childhood: a systematic review and metaanalysis of longitudinal studies. Allergy. 2018;73(3):696-704.

16. Thyssen JP, Andersen YMF, Zhang H, Gislason G, Skov L, Egeberg A. Incidence of pediatric atopic dermatitis following thymectomy: a Danish register study. Allergy. 2018;73(8):1741-3.

17. Lee JY, Kim M, Yang HK, Kim HM, Cho J, Kim YM, et al. Reliability and validity of the Atopic Dermatitis Symptom Score (ADSS). Pediatr Allergy Immunol. 2018;29(3):290-5.

18. Vakharia PP, Chopra R, Sacotte R, Patel N, Immaneni S, White T, et al. Validation of patient-reported global severity of atopic dermatitis in adults. Allergy. 2018;73(2):451-8.

19. Andersen YMF, Egeberg A, Hamann CR, Skov L, Gislason GH, Skaaby T, et al. Poor agreement in questionnaire-based diagnostic criteria for adult atopic dermatitis is a challenge when examining cardiovascular comorbidity. Allergy. 2018;73(4):923-31.

20. Hu JM, Lin CS, Chen SJ, Chen CY, Lin CL, Kao CH. Association between obstructive sleep apnea and atopic dermatitis in children: a nationwide, population-based cohort study. Pediatr Allergy Immunol. 2018;29(3):260-6.

21. Thyssen JP, Hamann CR, Linneberg A, Dantoft TM, Skov L, Gislason GH, et al. Atopic dermatitis is associated with anxiety, depression, and suicidal ideation, but not with psychiatric hospitalization or suicide. Allergy. 2018;73(1):214-20.

22. Schmitt J, Buske-Kirschbaum A, Tesch F, Trikojat K, Stephan V, Abraham $S$, et al. Increased attention-deficit/hyperactivity symptoms in atopic dermatitis are associated with history of antihistamine use. Allergy. 2018;73(3):615-26.

23. Thostesen LM, Kjaergaard J, Pihl GT, Birk NM, Nissen TN, Aaby P, et al. Neonatal BCG vaccination and atopic dermatitis before 13 months of age: a randomized clinical trial. Allergy. 2018;73(2):498-504

24. Baek JO, Lee JR, Roh JY, Jung Y. Oral tolerance modulates the skin transcriptome in mice with induced atopic dermatitis. Allergy. 2018;73(4):962-6.

25. Taghavi Ardakani A, Farrehi M, Sharif MR, Ostadmohammadi V, Mirhosseini $N$, Kheirkhah $D$, et al. The effects of melatonin administration on disease severity and sleep quality in children with atopic dermatitis: a randomized, double-blinded, placebo-controlled trial. Pediatr Allergy Immunol. 2018;29(8):834-40.

26. Shin JU, Kim SH, Noh JY, Kim JH, Kim HR, Jeong KY, et al. Allergen-specific immunotherapy induces regulatory $T$ cells in an atopic dermatitis mouse model. Allergy. 2018;73(9):1801-11.

27. Sah SK, Agrahari G, Nguyen CT, Kim Y-S, Kang K-S, Kim T-Y. Enhanced therapeutic effects of human mesenchymal stem cells transduced with superoxide dismutase 3 in a murine atopic dermatitis-like skin inflammation model. Allergy. 2018;73(12):2364-76.

28. Yu J, Liu X, Li Y, Meng S, Wu F, Yan B, et al. Maternal exposure to farming environment protects offspring against allergic diseases by modulating the neonatal TLR-Tregs-Th axis. Clin Transl Allergy. 2018;8:34.

29. Gedon NKY, Mueller RS. Atopic dermatitis in cats and dogs: a difficult disease for animals and owners. Clin Transl Allergy. 2018;8:41.

30. Napolitano M, Gallo R, Donnarumma M, Patruno C. Salt-dependent aquagenic urticaria in children: report of two cases. Pediatr Allergy Immunol. 2018;29(3):324-6.

31. Napolitano M, Patruno C. Chronic urticaria can be caused by cancer and resolves with its cure. Allergy. 2018;73(8):1750-1.

32. Larenas-Linnemann D, Saini SS, Azamar-Jácome AA, Jensen-Jarolim E, Maurer M. Very rarely chronic urticaria can be caused by cancer and if so, resolves with its cure. Allergy. 2018;73(9):1925-6.

33. Yon DK, Cho YS, Ha EK, Jee HM, Song JY, Jung YH, et al. Exposure to phthalates is associated with acute urticaria in children. Pediatr Allergy Immunol. 2018:29(6):657-60.
34. Altrichter S, Hawro T, Liedtke M, Holtappels G, Bachert C, Skov PS, et al. In chronic spontaneous urticaria, IgE against staphylococcal enterotoxins is common and functional. Allergy. 2018;73(7):1497-504

35. Kolkhir P, Altrichter S, Hawro T, Maurer M. C-reactive protein is linked to disease activity, impact, and response to treatment in patients with chronic spontaneous urticaria. Allergy. 2018;73(4):940-8.

36. Tuchinda P, Kulthanan K, Chularojanamontri L, Arunkajohnsak S, Sriussadaporn S. Relationship between vitamin D and chronic spontaneous urticaria: a systematic review. Clin Transl Allergy. 2018;8:51.

37. Balp MM, Weller K, Carboni V, Chirilov A, Papavassilis C, Severin T, et al. Prevalence and clinical characteristics of chronic spontaneous urticaria in pediatric patients. Pediatr Allergy Immunol. 2018;29(6):630-6.

38. Cornillier H, Giraudeau B, Munck S, Hacard F, Jonville-Bera AP, d'Acremont $\mathrm{G}$, et al. Chronic spontaneous urticaria in children-a systematic review on interventions and comorbidities. Pediatr Allergy Immunol. 2018;29(3):303-10.

39. Sussman G, Abuzakouk M, Berard F, Canonica W, Oude Elberink H, Gimenez-Arnau A, et al. Angioedema in chronic spontaneous urticaria is under diagnosed and has a substantial impact: analyses from ASSURECSU. Allergy. 2018;73(8):1724-34.

40. Maurer M, Magerl M, Ansotegui I, Aygören-Pürsün E, Betschel S, Bork $\mathrm{K}$, et al. The international WAO/EAACl guideline for the management of hereditary angioedema — the 2017 revision and update. Allergy. 2018;73(8):1575-96.

41. Riedl MA, Aygören-Pürsün E, Baker J, Farkas H, Anderson J, Bernstein $J A$, et al. Evaluation of avoralstat, an oral kallikrein inhibitor, in a Phase 3 hereditary angioedema prophylaxis trial: the OPuS-2 study. Allergy. 2018;73(9):1871-80

42. Veszeli N, Kohalmi KV, Kajdacsi E, Gulyas D, Temesszentandrasi G, Cervenak $L$, et al. Complete kinetic follow-up of symptoms and complement parameters during a hereditary angioedema attack. Allergy. 2018;73(2):516-20.

43. Bork K, Wulff K, Steinmüller-Magin L, Brænne I, Staubach-Renz P, Witzke G, et al. Hereditary angioedema with a mutation in the plasminogen gene. Allergy. 2018;73(2):442-50.

44. Dressler C, Rosumeck S, Werner RN, Magerl M, Metz M, Maurer M, et al. Executive summary of the methods report for 'The EAACI/GA(2) LEN/ EDF/WAO Guideline for the Definition, Classification, Diagnosis and Management of Urticaria. The 2017 Revision and Update'. Allergy. 2018;73(5):1145-6.

45. Zuberbier T, Aberer W, Asero R, Abdul Latiff AH, Baker D, Ballmer-Weber $B$, et al. The EAACI/GA(2)LEN/EDF/WAO guideline for the definition, classification, diagnosis and management of urticaria. Allergy. 2018;73(7):1393-414.

46. Zuberbier T, Bernstein JA. A comparison of the United States and International Perspective on Chronic Urticaria Guidelines. J Allergy Clin Immunol Pract. 2018;6(4):1144-51.

47. Hawro T, Ohanyan T, Schoepke N, Metz M, Peveling-Oberhag A, Staubach $P$, et al. Comparison and interpretability of the available urticaria activity scores. Allergy. 2018;73(1):251-5.

48. Lin $\mathrm{CH}$, Hung PH, Hu HY, Chung CJ, Chen TH, Hung KY. Clinically diagnosed urticaria and risk of systemic lupus erythematosus in children: a nationwide population-based case-control study. Pediatr Allergy Immunol. 2018;29(7):732-9

49. Kolkhir P, Pereverzina N, Olisova O, Maurer M. Comorbidity of viral hepatitis and chronic spontaneous urticaria: a systematic review. Allergy. 2018;73(10):1946-53.

50. Weller K, Church MK, Hawro T, Altrichter S, Labeaga L, Magerl M, et al. Updosing of bilastine is effective in moderate to severe chronic spontaneous urticaria: a real-life study. Allergy. 2018;73(10):2073-5.

51. Staubach P, Metz M, Chapman-Rothe N, Sieder C, Brautigam M, Maurer $M$, et al. Omalizumab rapidly improves angioedema-related quality of life in adult patients with chronic spontaneous urticaria: X-ACT study data. Allergy. 2018;73(3):576-84.

52. Caballero T, Zanichelli A, Aberer W, Maurer M, Longhurst HJ, Bouillet $L$, et al. Effectiveness of icatibant for treatment of hereditary angioedema attacks is not affected by body weight: findings from the Icatibant Outcome Survey, a cohort observational study. Clin Transl Allergy. 2018;8:11.

53. de Brito M, Huebner G, Murrell D, Bullpitt P, Hartmann K. Normocomplementaemic urticarial vasculitis: effective treatment with omalizumab. Clin Transl Allergy. 2018;8:37. 
54. Cugno M, Asero R, Ferrucci S, Lorini M, Carbonelli V, Tedeschi A, et al. Elevated IgE to tissue factor and thyroglobulin are abated by omalizumab in chronic spontaneous urticaria. Allergy. 2018;73(12):2408-11.

55. Weller K, Ohanyan T, Hawro T, Ellrich A, Sussman G, Koplowitz J, et al. Total lgE levels are linked to the response of chronic spontaneous urticaria patients to omalizumab. Allergy. 2018;73(12):2406-8.

56. Ertas R, Ozyurt K, Atasoy M, Hawro T, Maurer M. The clinical response to omalizumab in chronic spontaneous urticaria patients is linked to and predicted by IgE levels and their change. Allergy. 2018:73(3):705-12

57. Asero R. Efficacy of omalizumab $150 \mathrm{mg} / \mathrm{month}$ as a maintenance dose in patients with severe chronic spontaneous urticaria showing a prompt and complete response to the drug. Allergy. 2018;73(11):2242-4.
58. Eapen A, Kloepfer KM. Serum sickness-like reaction in a pediatric patient using omalizumab for chronic spontaneous urticaria. Pediatr Allergy Immunol. 2018:29(4):449-50.

\section{Publisher's Note}

Springer Nature remains neutral with regard to jurisdictional claims in published maps and institutional affiliations.
Ready to submit your research? Choose BMC and benefit from:

- fast, convenient online submission

- thorough peer review by experienced researchers in your field

- rapid publication on acceptance

- support for research data, including large and complex data types

- gold Open Access which fosters wider collaboration and increased citations

- maximum visibility for your research: over $100 \mathrm{M}$ website views per year

At BMC, research is always in progress.

Learn more biomedcentral.com/submissions 